\title{
In Vitro Study of DP-bioglass Paste for Treatment of Dentin Hypersensitivity
}

\author{
Bor-Shiunn LEE, Hsin-Yi TSAI, Yi-Ling TSAI, Wan-Hong LAN and Chun-Pin LIN \\ Graduate Institute of Clinical Dentistry, College of Medicine, National Taiwan University and National Taiwan University \\ Hospital, Taipei, Taiwan \\ Corresponding author, Chun-Pin Lin E-mail:pinlin@ha.mc.ntu.edu.tw
}

Received July 7, 2005/Accepted September 14, 2005

\begin{abstract}
Sealing of exposed dentinal tubules is generally considered the most effective strategy to treat dentin hypersensitivity. On this account, we fabricated a DP-bioglass paste that created a homogeneous blockage on open dentinal tubules and formed a deep precipitate within dentinal tubules. DP-bioglass paste was prepared by mixing $20 \%$ to $60 \%$ phosphoric acid and DPbioglass to treat dentin surfaces. $\mathrm{CO}_{2}$ laser irradiation was used to melt the DP-bioglass paste. The results demonstrated that $30 \%$ phosphoric acid was the optimum concentration to produce homogeneous occlusion on exposed dentinal tubules and $60 \mu \mathrm{m}$ of sealing depth. $\mathrm{CO}_{2}$ laser irradiation could melt the DP-bioglass paste and create about $10 \mu \mathrm{m}$ of sealing depth. Moreover, temperature rise during $\mathrm{CO}_{2}$ laser irradiation was only $4.86 \pm 0.47^{\circ} \mathrm{C}$. The results presented in this work suggested that DP-bioglass paste could produce considerable sealing depth in dentinal tubules with the potential of prolonging the therapeutic effect efficaciously.
\end{abstract}

Key words : DP-bioglass, $\mathrm{CO}_{2}$ laser, Dentin hypersensitivity

\section{INTRODUCTION}

Dentin hypersensitivity is an annoying symptom afflicting numerous patients, particularly and prevalently among those in the age groups of 20-29.9 years $(34.9 \%)$ and $30-39.9$ years $(33.3 \%)^{1 /}$. Dentin hypersensitivity is typically characterized by brief, sharp pain that occurs in response to thermal, tactile, osmotic, chemical, or evaporative stimuli and which cannot be attributed to any form of pathology or dental defect ${ }^{2)}$. Sensitivity is strongest with cold stimuli $^{3)}$ probably because fluid flows away from the pulp, thereby producing a greater pulp nerve response, as compared to a stimulus that causes an inward flow such as heat ${ }^{4)}$. Intraoral distribution study revealed that premolars and molars were the predominantly affected teeth, while the incisors were the least sensitive ones ${ }^{5 \text { ? }}$.

Dentin hypersensitivity is intimately associated with exposed dentinal tubules ${ }^{6)}$. When comparisons were made between sensitive and non-sensitive dentin, it was found that the number of patent dentinal tubules was $35.6 \%$ in the former and $9.3 \%$ in the latter $^{7)}$. In addition, the diameter of dentinal tubules was wider $(0.83 \mu \mathrm{m})$ in sensitive dentin than in nonsensitive dentin $(0.43 \mu \mathrm{m})^{8)}$. Exposure of dentinal tubules may be ascribed to many causative factors, such as attrition from occlusal wear, abrasive tooth brushing, dietary erosion, parafunctional habits, gingival recession, aging, chronic periodontal disease, periodontal surgery, root preparation, and abfractive lesions ${ }^{9)}$. In these circumstances, the odontoblastic processes inside the open dentinal tubules are sensitive to external irritation.

Among the theories proposed to explain the mechanism of dentin hypersensitivity, the most broadly accepted theory is the hydrodynamic theory, which states that stimulus application induces pressure changes across dentin. As a result of the pressure changes, rapid shifts of fluids take place within the dentinal tubules, followed by excitation of sensory nerves in the pulp dentin border ${ }^{10)}$. Therefore, using physical agents to reduce the excitability of the relevant sensory nerves or chemical agents to block the exposed dentinal tubules are practicable methods to treat dentin hypersensitivity. The PoiseuilleHagen equation demonstrates the pressure difference between two ends of a tubule, and it also shows that the movement of the dentinal fluid in a tubule is proportional to the fourth power of tubular radius ${ }^{11}$. Consequently, dentin hypersensitivity can be successfully treated by permanently blocking the exposed dentinal tubules in order to reduce fluid flow.

Physical agents that have been suggested included Nd:YAG laser ${ }^{12)}$ and GaAlAs laser ${ }^{13)}$, while chemical agents were namely ferric oxalate ${ }^{14)}$, potassium nitrate ${ }^{15)}$, visible light-cured materials ${ }^{16)}$, and fluoride varnishes ${ }^{17)}$. Although these materials were reported to be effective, their therapeutic effects were generally short-lived or diminished with time because these agents could be easily removed by daily tooth brushing or acidic beverage drinking. Consequently, to produce a long-lasting seal, the material must penetrate the dentinal tubules and occlude the orifices of dentinal tubules.

Suge et $a{ }^{18)}$ has reported that a calcium phosphate precipitation (CPP) method could achieve 10 to $15 \mu \mathrm{m}$ of sealing depth into the dentinal tubules. If a deeper sealing depth could be created, then a longer therapeutic effect could be expected. After treatment 
with CPP solution, the dentinal surfaces were further neutralized by $1.0 \mathrm{~mol} / \mathrm{L} \mathrm{NaOH}$ as a post-treatment solution. However, the basic solution could cause atrophy and degeneration of gingival epithelium ${ }^{19)}$.

Bioglass is a highly biocompatible material. We have used the bioglass combined with laser treatment to achieve $10 \mu \mathrm{m}$ of sealing depth for dentinal tubules $^{20)}$. In this in vitro study, we fabricated DPbioglass paste and applied $\mathrm{CO}_{2}$ laser to melt the bioglass with the intent of creating a deeper seal within the dentinal tubules. The microstructure and crystalline structure of DP-bioglass paste were examined using scanning electron microscopy-energy dispersive X-ray spectroscopy (SEM-EDX) and X-ray diffractometry (XRD) respectively. In addition, the thermal effect of $\mathrm{CO}_{2}$ laser was also evaluated.

\section{MATERIALS AND METHODS}

\section{DP-bioglass paste preparation}

The DP-bioglass used in this study was based on a $\mathrm{Na}_{2} \mathrm{O}-\mathrm{CaO}-\mathrm{SiO}_{2}-\mathrm{P}_{2} \mathrm{O}_{5}$ system. Powder mixture of the nominal composition of $\mathrm{Na}_{2} \mathrm{O} 8.4 \%, \mathrm{CaO} 40.6 \%, \mathrm{SiO}_{2}$ $39 \%, \mathrm{P}_{2} \mathrm{O}_{5} 12 \%$ in weight ratio was mixed in a ball mill pot, and $100 \mathrm{ml}$ of ethanol was added to wet-mill the powder together for eight hours. The powder was dried overnight in an oven at $80^{\circ} \mathrm{C}$ to remove the ethanol. This homogeneous powder was placed in a platinum crucible and heated in a SiC furnace to 1410 ${ }^{\circ} \mathrm{C}$ for 1.5 hours. The melted glass was then removed from the furnace and poured into $0^{\circ} \mathrm{C}$ ice water to be quenched into glass frit. All glass frit was pulverized by a Spex 8000 alumina ball mill and sieved to a powder less than $53 \mu \mathrm{m}$. The DP-bioglass powder was mixed with $60 \%, 50 \%, 40 \%, 30 \%$, or $20 \%$ phosphoric acid aqueous solution in a powder/liquid ratio of $0.05 \mathrm{~g} / 0.1 \mathrm{ml}$ to form five types of DP-bioglass paste.

\section{Specimens preparation}

Sixty extracted human third molars from 16- to 40year-old individuals with informed consent at the $\mathrm{Na}$ tional Taiwan University Hospital were used for this study. Crowns with caries, restoration, or fracture were discarded. Any remaining soft tissue was thoroughly removed from the tooth surface with a dental scaler (Sonicflex 2000, KaVo Co., Biberbach, Germany). All teeth were then stored in $4{ }^{\circ} \mathrm{C}$ distilled water containing $0.2 \%$ thymol to inhibit microbial growth until use.

While hydrated, crown dentin discs with 3-mm thickness were cut perpendicular to the long axis of the tooth by means of a low-speed diamond wafering blade (Isomet; Buehler Ltd., Lake Bluff, IL). Each specimen was immersed in 17\% EDTA followed by two minutes of ultrasonic vibration to remove the smear layer, then rinsed with copious distilled water and dried with clean air. These dentin discs were divided into four groups (A to D) with 15 in each group for DP-bioglass paste treatment. Each group was further subdivided into five subgroups to receive five types of DP-bioglass paste. Group A was designated to examine the occlusive effect of DP-bioglass paste on the orifices of dentinal tubules, whereas Groups $\mathrm{B}$ and $\mathrm{C}$ were to be evaluated in terms of the sealing depth of DP-bioglass paste and $\mathrm{Ca} / \mathrm{P}$ ratio of precipitation respectively. A groove was prepared using tapered fissure bur on the specimens of Groups $\mathrm{B}$ and $\mathrm{C}$ to facilitate the sectioning of specimens with a chisel. Group D was designated to receive DPbioglass paste with $\mathrm{CO}_{2}$ laser irradiation. We applied the DP-bioglass paste (powder/liquid ratio of $0.05 \mathrm{~g}$ / $0.1 \mathrm{ml}$ ) to the specimens for one minute with an applicator sponge, and then stored all specimens (Groups A to D) in $37^{\circ} \mathrm{C}, 100 \%$ humidity environment for three days to simulate the oral cavity and enable the DP-bioglass paste to take occlusive effect. The sealing depth of dentinal tubules from the dentinal surface to the bottom of DP-bioglass was measured in 20 dentinal tubules obtained from three independently treated specimens ${ }^{18)}$.

\section{Laser treatment}

A $\mathrm{CO}_{2}$ laser (Sharplan 1030, Sharplan Lasers Inc., USA) that provided a constant beam of coherent, continuous monochromatic light with an emission wavelength of $10.6 \mu \mathrm{m}$ and a spot size diameter of 0.8 $\mathrm{mm}$ was used in this study. The laser was delivered with a straight handpiece, and the laser tip was held perpendicular to the irradiated surface and $1 \mathrm{~mm}$ away to prevent contamination from vaporized DPbioglass and dentin. After application on a thin film of DP-bioglass paste, the laser tip swept in a mesiodistal fashion with an irradiation area of approximately $3 \mathrm{~mm} \times 2 \mathrm{~mm}$ and a speed of about 3 $\mathrm{mm} / \mathrm{sec}$ - up to a total irradiation time of two seconds - to simulate clinical manipulation. Energy density of target surface following irradiation was $100 \mathrm{~J} / \mathrm{cm}^{2}$.

Scanning electron microscopy-energy dispersive $X$-ray spectroscopy (SEM-EDX) examination

The occlusive effect, microstructure, sealing depth, and $\mathrm{Ca} / \mathrm{P}$ ratio of $\mathrm{DP}$-bioglass paste were observed using SEM-EDX. The specimens were immersed in $2.5 \%$ cold glutaraldehyde in $0.1 \mathrm{~mol} / \mathrm{L}$ cacodylate buffer at $\mathrm{pH} 7.4$ for eight hours. All specimens were then serially dehydrated in graded ethanol solutions $(50 \%, 60 \%, 70 \%, 80 \%, 90 \%, 95 \%$, and $100 \%$ ethanol) at 45-minute intervals, critical point dried in $\mathrm{CO}_{2}$, mounted on aluminum stubs, sputter-coated with $\sim 20 \mathrm{~nm}$ of carbon, and finally examined by a SEM (Model S-800, Hitachi , Tokyo, Japan) at an accelerating voltage of $15 \mathrm{kV}$. 


\section{Temperature elevation measurement}

Ten extracted human upper premolars were used in measuring temperature increase during $\mathrm{CO}_{2}$ laser treatment. Teeth were sectioned longitudinally from the central groove of each occlusal surface with a low-speed diamond wafering blade to obtain 20 specimens. The buccal or lingual cervical regions with dimensions of about $3 \mathrm{~mm} \times 2 \mathrm{~mm}$ were wet-polished with 600 grit silicon carbide paper to remove the enamel and cementum, etched with $37 \%$ phosphoric acid solution for 30 seconds, rinsed with copious distilled water, and dried with clean air to expose the dentinal tubules and prepare them for subsequent laser treatment. The site of the pulp cavity corresponding to the outer lased area was slightly polished with 600 grit silicon carbide paper until the thickness was $2.5 \mathrm{~mm}$. Then, the site of the pulp cavity was applied with a silicone heat transfer compound (Unick, Unick Chemical Co., Taipei, Taiwan) to promote heat conduction in a thermocouple (type K025, diameter $0.25 \mathrm{~mm}$, Philips, Tokyo, Japan). Paraffin wax was used to isolate the thermocouple from influences caused by environmental temperature. The thermocouple was connected to a digital oscilloscope (9310M, Dual $300 \mathrm{MHz}$, LeCroy Corp., Geneva, Switzerland), X-Y plotter (DXY-880, Roland Digital Group Co., Tokyo, Japan), and digital thermometer (YF-160, Type K, Yu Hong Co., Taipei, Taiwan) to record the mean temperature elevation and standard deviation. One-way analysis of variance followed by Student's t-test was used to examine the statistical significant difference of temperature rise.

Twenty specimens were randomly divided into two groups. One group received DP-bioglass paste with $\mathrm{CO}_{2}$ laser irradiation, while the other group received $\mathrm{CO}_{2}$ laser treatment only. The operation mode of laser irradiation was the same as that of specimens for SEM-EDX observation.

\section{$X$-ray diffraction $(X R D)$ analysis}

Crystalline phases of the DP-bioglass paste before and after mixing with phosphoric acid were determined by a X-ray powder diffractometer (Rigaku Denki Co., Ltd., Tokyo, Japan) with $\mathrm{CuK} \alpha$ radiation and $\mathrm{Ni}$ filter. Scanning range was 10 degrees to 60 degrees, with a scanning speed of 4 degrees $/ \mathrm{min}$. To determine the contents of different phases, relative intensities of the characteristic peaks of each phase were used.

\section{RESULTS}

Scanning electron microscopy-energy dispersive X-ray spectroscopy (SEM-EDX) examination

The dentin specimen after 17\% EDTA and two minutes of ultrasonic vibration exhibited a clean and even surface (Fig. 1(a)). There was no smear layer and exposed dentinal tubules' orifices were noted.
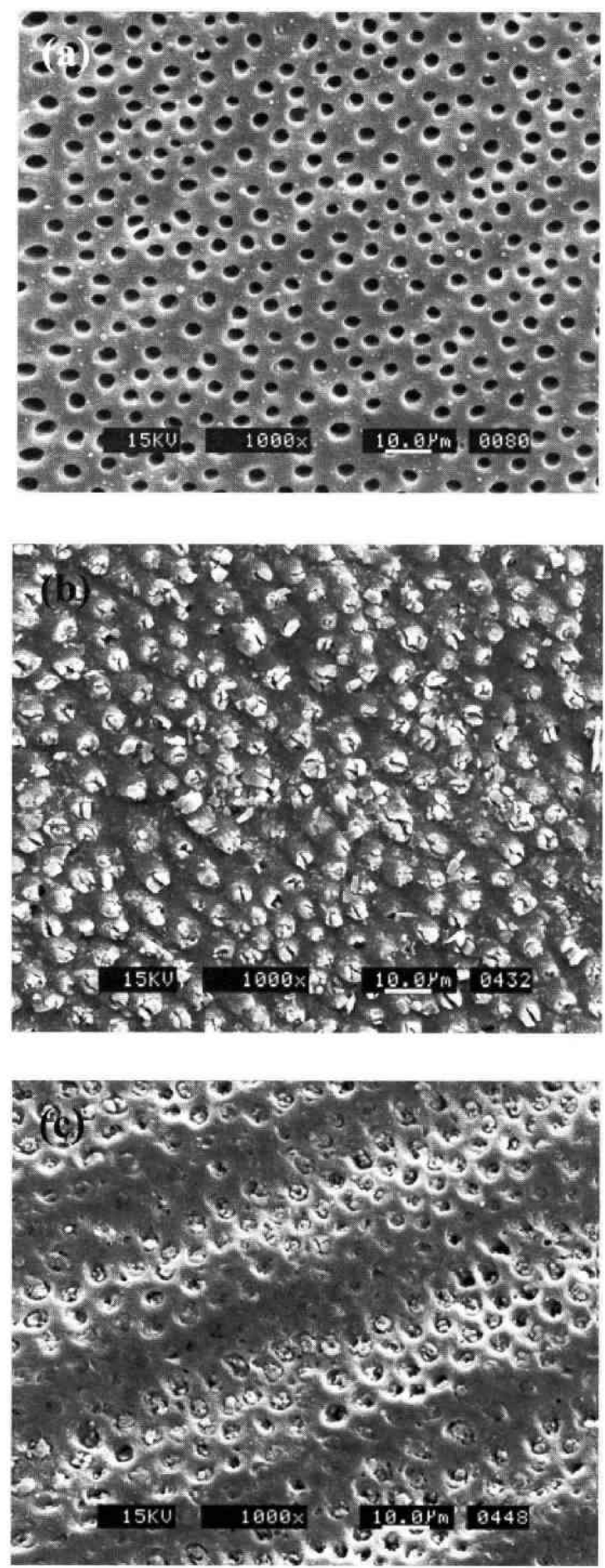

Fig. 1 (a) SEM micrograph of dentin surface treated with EDTA and 2 minutes of ultrasonic vibration. A clear and even surface free of smear layer was found on the dentin specimen. (b) SEM micrograph of DP-bioglass paste application mixed with $30 \%$ phosphoric acid. The orifices of dentinal tubules were completely occluded. (c) SEM micrograph of DP-bioglass paste application mixed with $20 \%$ phosphoric acid. Incomplete coverings with many exposed dentinal tubules were noted. 

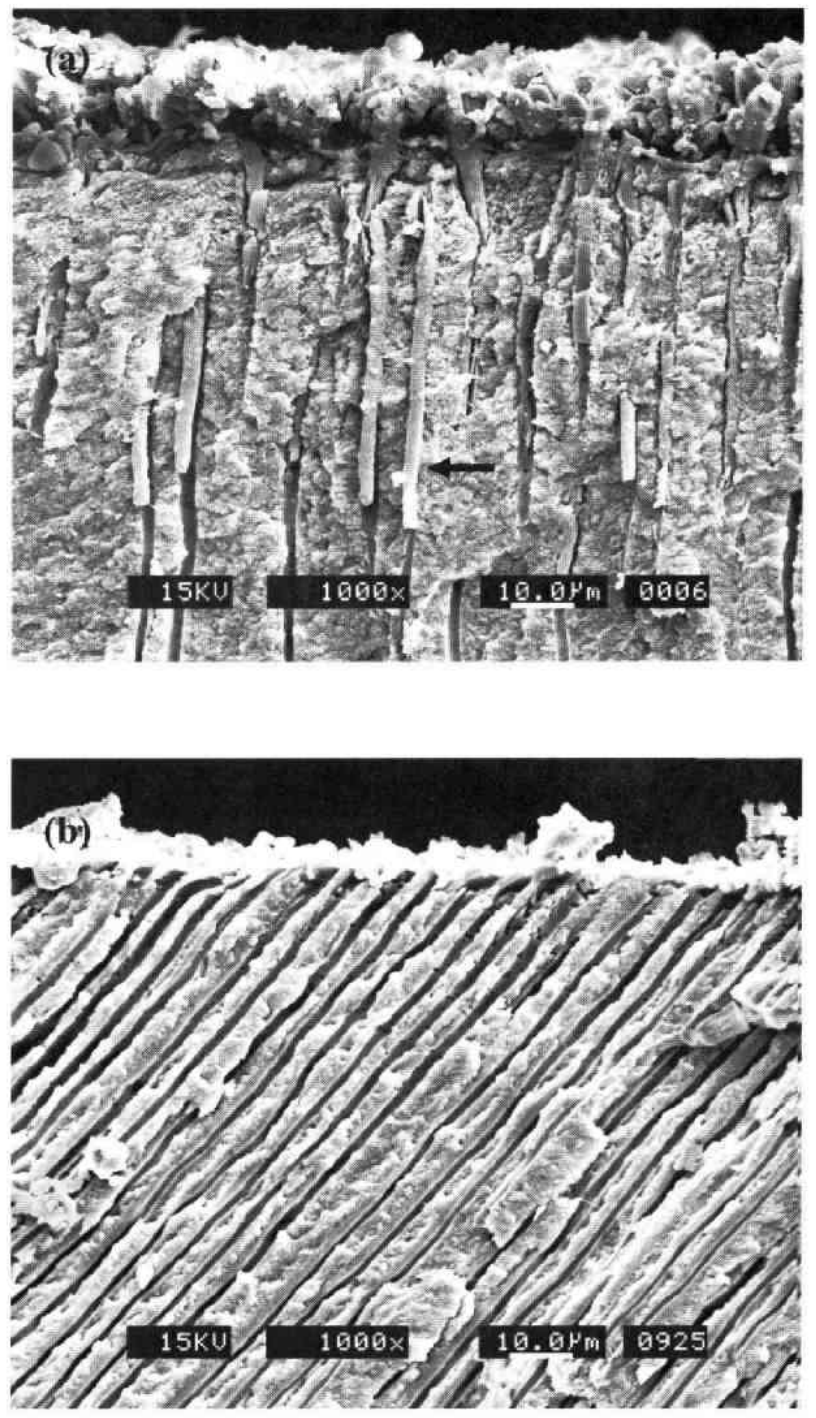

Fig. 2 (a) SEM micrograph of a longitudinal section parallel to the direction of dentinal tubules alignment. Sealing depth of DP-bioglass paste could be as deep as $60 \mu \mathrm{m}$ when the concentration of phosphoric acid was $30 \%$ and above (arrow). (b) No sealing depth could be found when concentration of phosphoric acid was $20 \%$.

Fig. 1(b) shows that the orifices of dentinal tubules were completely covered by DP-bioglass mixed with $30 \%$ phosphoric acid. Application of DP-bioglass mixed with $40 \%, 50 \%$, and $60 \%$ phosphoric acid produced similar occlusive effect on the orifices of dentinal tubules. However, when the concentration of phosphoric acid was decreased to $20 \%$, a reduced sealing effect on dentinal tubules could be observed (Fig. 1(c)). Indeed, it could be seen that many exposed dentinal tubules were not occluded. From the longitudinal section parallel to the direction of dentinal tubules alignment, the sealing depth could be as deep as $60 \mu \mathrm{m}$ when the concentration of
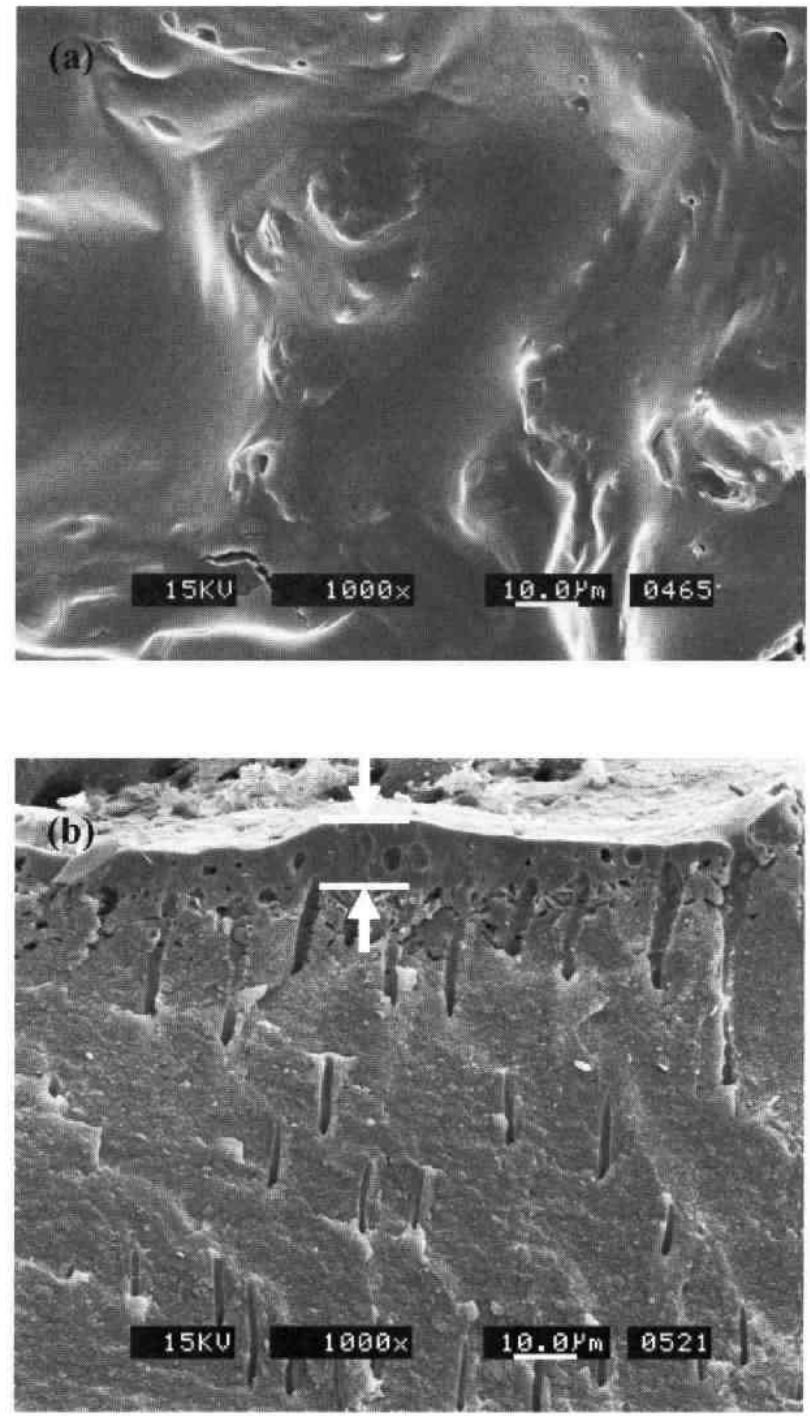

Fig. 3 (a) SEM micrograph of DP-bioglass paste after $\mathrm{CO}_{2}$ laser irradiation. It shows a homogeneous, glassy, and melted surface with no exposed dentinal tubules. (b) Sealing depth was about 10 $\mu \mathrm{m}$ (between white arrows).

phosphoric acid was $30 \%$ and above (Fig. 2(a)). In contrast to the deep penetration, no sealing depth could be found when the concentration of phosphoric acid was $20 \%$ (Fig. 2(b)).

When DP-bioglass paste was irradiated by $\mathrm{CO}_{2}$ laser, a homogeneous, glassy, and melted surface with no exposed dentinal tubules was obtained (Fig. $3(\mathrm{a})$ ). This phenomenon could be found irrespective of the concentration of phosphoric acid. The sealing depth was about $10 \mu \mathrm{m}$ (Fig. 3(b)).

Table 1 demonstrates the $\mathrm{Ca} / \mathrm{P}$ ratio of $\mathrm{DP}$ bioglass precipitation inside the dentinal tubules. Examined sites were located $5,20,50 \mu \mathrm{m}$ from the 
Table $1 \mathrm{Ca} / \mathrm{P}$ ratio of DP-bioglass precipitation inside dentinal tubules by X-ray quantitative analysis

\begin{tabular}{cccc}
\hline \multirow{2}{*}{ Concentration of phosphoric acid } & \multicolumn{3}{c}{ Area examined from the orifices of dentinal tubules } \\
\cline { 2 - 4 } & $5 \mu \mathrm{m}$ & $20 \mu \mathrm{m}$ & $50 \mu \mathrm{m}$ \\
\hline $30 \%$ & 1.17 & 1.26 & 1.42 \\
$40 \%$ & 1.14 & 1.27 & 1.41 \\
$50 \%$ & 1.13 & 1.22 & 1.34 \\
$60 \%$ & 1.10 & 1.21 & 1.36 \\
\hline
\end{tabular}

Table 2 Mean temperature rise and standard deviation after $\mathrm{CO}_{2}$ laser irradiation

\begin{tabular}{lr}
\hline \multicolumn{1}{c}{ Group } & Temperature rise $\left({ }^{\circ} \mathrm{C}\right)$ \\
\hline No DP-bioglass application & $17.75 \pm 1.12(10)^{* a}$ \\
DP-bioglass application & $4.86 \pm 0.47(10)^{*}$ \\
\hline
\end{tabular}

Significant $(\mathrm{P}<0.05)$ by Student's $t$-test with one-way analysis of variance.

${ }^{a}$ Values are means (standard deviation) (number of specimens).

orifices of dentinal tubules. As the depth increased, the $\mathrm{Ca} / \mathrm{P}$ ratio also became greater. No peculiar relationship could be found among different concentrations of phosphoric acid.

\section{Temperature elevation measurement}

Table 2 demonstrates the mean temperature rise and standard deviation with and without DP-bioglass application after $\mathrm{CO}_{2}$ laser irradiation. Temperature was elevated to $17.75 \pm 1.12^{\circ} \mathrm{C}$ when DP-bioglass paste was not applied. However, the temperature rise decreased to $4.86 \pm 0.47^{\circ} \mathrm{C}$ when DP-bioglass paste was used. There was a significant difference between these two groups.

\section{$X$-ray diffraction $(X R D)$ analysis}

Fig. 4 shows the XRD diffraction patterns of DPbioglass mixed with different concentrations of phosphoric acid. Before mixing with phosphoric acid, DPbioglass exhibited an amorphous pattern without any characteristic peak (Fig. 4(a)). When the concentration of phosphoric acid was $40 \%$ and above, prominent crystalline peaks could be observed at the positions of $2 \theta=23.1^{\circ}, 24.2^{\circ}, 30.6^{\circ}$ (Figs. 4 (b), (c), (d)). Compared with the standard JCPDs card, the crystalline phase that existed in the DP-bioglass paste was identified as calcium phosphate monohydrate $\left(\mathrm{Ca}\left(\mathrm{H}_{2} \mathrm{PO}_{4}\right)_{2} \cdot \mathrm{H}_{2} \mathrm{O}\right)$. As the concentration of phosphoric acid was decreased to $30 \%$ and $20 \%$, the characteristic peaks shifted to the positions of $2 \theta=11.6^{\circ}$, $21.0^{\circ}, 29.3^{\circ}$ (Figs. $4(\mathrm{e})$, (f)). These peaks indicated that the major crystalline compound of DP-bioglass paste was dicalcium phosphate dihydrate $\left(\mathrm{CaHPO}_{4}\right.$. $2 \mathrm{H}_{2} \mathrm{O}$ ).

The XRD diffraction patterns of DP-bioglass

$$
\text { - } \mathrm{Ca}\left(\mathrm{H}_{2} \mathrm{PO}_{4}\right)_{2} \cdot \mathrm{H}_{2} \mathrm{O} \wedge \mathrm{CaHPO}_{4} \cdot 2 \mathrm{H}_{2} \mathrm{O}
$$

(a)

(b)

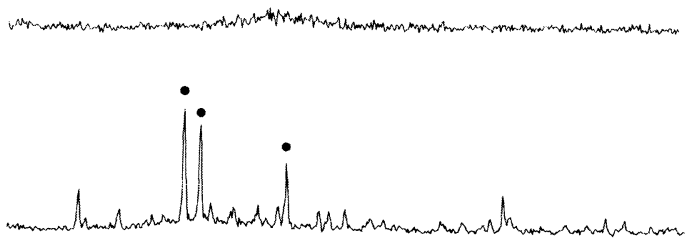

(c)

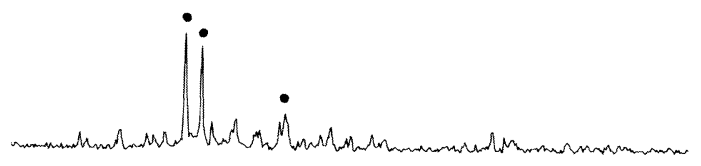

(d)

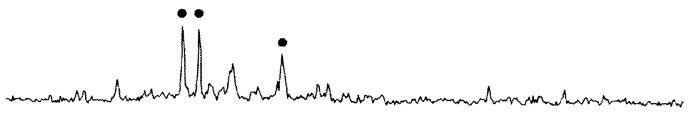

(e)

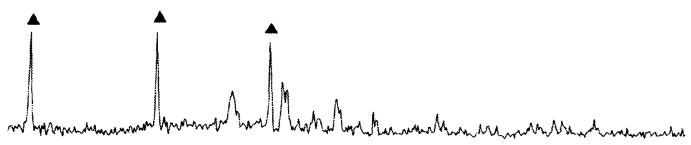

(f)

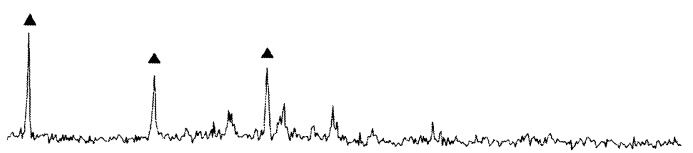

$\begin{array}{lllll}10 & 30 & 30 & 50 & 60\end{array}$

Fig. 4 XRD diffraction pattern of (a) DP-bioglass and DP-bioglass mixed with (b) $60 \%$, (c) $50 \%$, (d) $40 \%$, (e) $30 \%$, and (f) $20 \%$ phosphoric acid. DPbioglass exhibited an amorphous pattern without any characteristic peak. When concentration of phosphoric acid was $40 \%$ and above, the crystalline phase that existed in the DP-bioglass paste was calcium phosphate monohydrate $\left(\mathrm{Ca}\left(\mathrm{H}_{2} \mathrm{PO}_{4}\right)_{2}\right.$. $\left.\mathrm{H}_{2} \mathrm{O}\right)$. As the concentration of phosphoric acid was decreased to $30 \%$ and $20 \%$, the major crystalline compound of DP-bioglass paste was dicalcium phosphate dihydrate $\left(\mathrm{CaHPO}_{4} \cdot 2 \mathrm{H}_{2} \mathrm{O}\right)$. 
- $\mathrm{Ca}\left(\mathrm{H}_{2} \mathrm{PO}_{4}\right)_{2} \cdot \mathrm{H}_{2} \mathrm{O} \wedge \mathrm{CaHPO}_{4} \cdot 2 \mathrm{H}_{2} \mathrm{O}$

(a)

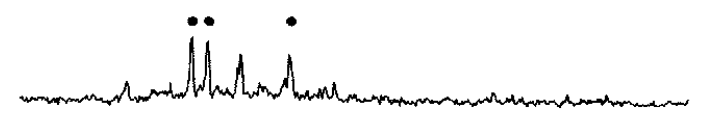

(b)

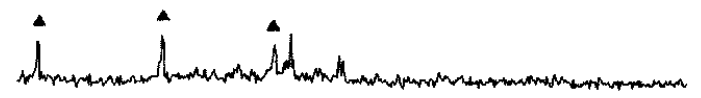

10

30

2 theta

Fig. 5 XRD diffraction pattern of DP-bioglass paste mixed with (a) $40 \%$ phosphoric acid and (b) $30 \%$ phosphoric acid after $\mathrm{CO}_{2}$ laser irradiation. Compared with those patterns before $\mathrm{CO}_{2}$ laser irradiation, they were of a similar profile but the magnitude of characteristic peaks was lower.

paste lased by $\mathrm{CO}_{2}$ laser shared a similar profile with those before $\mathrm{CO}_{2}$ laser irradiation, except that the characteristic peaks were of a lower magnitude (Figs. $5(\mathrm{a}),(\mathrm{b}))$.

\section{DISCUSSION}

Blockage of open dentinal tubules is generally accepted as the most effective strategy to treat dentin hypersensitivity. To resist the friction of daily tooth brushing and food chewing, the blockage should not only cover the exposed dentinal tubules but also penetrate the dentinal tubules as deeply as possible. Otherwise, therapeutic efficacy will be short-lived and repeated application of desensitizer will be indispensable $^{21)}$. Be it physical or chemical agents that have been proposed to achieve a considerable sealing depth, both entailed the use of calcium phosphate ${ }^{18)}$. By dissolving $\mathrm{Ca}(\mathrm{OH})_{2}$ or $\mathrm{CaHPO}_{4} \cdot 2 \mathrm{H}_{2} \mathrm{O}$ in $\mathrm{H}_{3} \mathrm{PO}_{4}$ or $\mathrm{HCl}$ and using $\mathrm{NaOH}$ as the post-treatment solution, approximately $15 \mu \mathrm{m}$ of sealing depth into dentinal tubules could be produced. In this study, application of DP-bioglass paste that was mixed with $30 \%$ phosphoric acid could produce a sealing depth of $60 \mu \mathrm{m}$ (Fig. 2 (a)) and could evenly cover the orifices of dentinal tubules (Fig. 1(b)). DP-bioglass that was mixed with $40 \%, 50 \%$, and $60 \%$ phosphoric acid resulted in similar occlusive effect, indicating the $30 \%$ phosphoric acid was the lowest effective concentration. With $20 \%$ phosphoric acid, such a homogeneous sealing effect was not obtained (Figs. 1(c), 2(b)). As 37\% phosphoric acid is generally employed to etch the dental hard tissues, DP-bioglass with $30 \%$ phosphoric acid should be tolerable and safe for pulp tissue.

DP-bioglass paste with $\mathrm{CO}_{2}$ laser irradiation has been proposed to treat tooth fractures ${ }^{22,23)}$. By means of transient high energy induced by $\mathrm{CO}_{2}$ laser, DPbioglass paste was anticipated to melt and flow into dentinal tubules. The results revealed that the dentinal surfaces were homogeneously covered by melted DP-bioglass paste and about $10 \mu \mathrm{m}$ of sealing depth could be achieved (Figs. 3(a), (b)). In addition, no recrystallization or grain growth was found after $\mathrm{CO}_{2}$ laser irradiation. This implied that $\mathrm{CO}_{2}$ laser energy could sufficiently melt the DP-bioglass paste and possibly the underlying dentin structure, hence making the two materials fuse together. The rapid cooling rate after $\mathrm{CO}_{2}$ laser irradiation could not allow any well-crystallized product to be formed $^{24)}$, and thus the XRD diffraction patterns of DP-bioglass paste lased by $\mathrm{CO}_{2}$ laser exhibited no sharp characteristic peaks (Figs. 5(a), (b)).

Using $\mathrm{CO}_{2}$ laser may raise another concern if the temperature rise proved harmful to the pulp tissue. To evaluate the thermal effect, we simulated the clinical condition by selecting premolars as the specimens since they are the teeth most likely to be afflicted. The cervical area was irradiated, and temperature rise in the pulp cavity was measured. The results demonstrated that temperature rise was 17.75 $\pm 1.12^{\circ} \mathrm{C}$ when DP-bioglass paste was not applied. Nevertheless, the temperature rise decreased to 4.86 $\pm 0.47^{\circ} \mathrm{C}$ when DP-bioglass paste was used. Zach and Cohen $^{25)}$ have reported on pulp response to externally applied heat. Their results showed that $15 \%$ of teeth failed to recover from an intrapulpal temperature increase of $5.5^{\circ} \mathrm{C}$ and $60 \%$ of teeth could not recover if the temperature increase was $11^{\circ} \mathrm{C}$. Therefore, temperature increase below $5.5^{\circ} \mathrm{C}$ produced only minimal intrapulpal changes and has been considered a safe threshold. Based on this report, temperature rise of $4.86 \pm 0.47^{\circ} \mathrm{C}$ would therefore cause no injury to pulp tissue when DP-bioglass paste was irradiated by $\mathrm{CO}_{2}$ laser. Furthermore, in vivo temperature rise due to laser treatment should be much lower because blood flow, blood perfusion, and heat conduction through gingival and bone would help dissipate the heat to the surrounding tissues ${ }^{26)}$.

When the concentration of phosphoric acid was $40 \%$ and above, the XRD diffraction patterns of DP-bioglass paste showed that the major crystalline phase was calcium phosphate monohydrate $\left(\mathrm{Ca}\left(\mathrm{H}_{2} \mathrm{PO}_{4}\right)_{2} \cdot \mathrm{H}_{2} \mathrm{O}\right)$ (Figs. 4(b), (c), (d)). As the concentration of phosphoric acid was decreased to $30 \%$ and $20 \%$, the major crystalline compound of DPbioglass paste was dicalcium phosphate dihydrate $\left(\mathrm{CaHPO}_{4} \cdot 2 \mathrm{H}_{2} \mathrm{O}\right)$ (Figs. $4(\mathrm{e})$, (f) ). The reactions were proposed as follows ${ }^{27)}$ :

$$
\begin{aligned}
& \left(\mathrm{SiO}^{-}\right)_{2} \mathrm{Ca}^{2+}+2 \mathrm{H}^{+}+2 \mathrm{H}_{2}\left(\mathrm{PO}_{4}\right)^{-}+\mathrm{H}_{2} \mathrm{O} \rightarrow \\
& \mathrm{Ca}\left(\mathrm{H}_{2} \mathrm{PO}_{4}\right)_{2} \cdot \mathrm{H}_{2} \mathrm{O}+2 \mathrm{SiOH} \\
& \left(\mathrm{SiO}^{-}\right)_{2} \mathrm{Ca}^{2+}+\mathrm{H}^{+}+\mathrm{H}_{2}\left(\mathrm{PO}_{4}\right)^{-}+2 \mathrm{H}_{2} \mathrm{O} \rightarrow \\
& \mathrm{CaHPO}_{4} \cdot 2 \mathrm{H}_{2} \mathrm{O}+2 \mathrm{SiOH}
\end{aligned}
$$

SEM-EDX examination revealed that the $\mathrm{Ca} / \mathrm{P}$ ratio of DP-bioglass precipitation inside dentinal 
tubules ranged from 1.10 to 1.42 (Table 1). As the depth of the examined site increased, the $\mathrm{Ca} / \mathrm{P}$ ratio also became greater. This implied that the deeper precipitate was more apatite-like and more resistant to hydrolysis.

The mechanism of precipitate formation inside the dentinal tubules was assumed to proceed as follows. First, DP-bioglass was melted by phosphoric acid, and then calcium as well as phosphate ions were released. Second, the ions and remnant phosphoric acid diffused into the dentinal tubules, and peritubular dentin was dissolved by phosphoric acid. Third, the dissolved ions from peritubular dentin, calcium ions, and phosphate ions altogether formed the precipitate. If the precipitate could receive $\mathrm{Ca}^{2+}$ from the pulpal fluid in vivo, it is possible for dicalcium phosphate dihydrate $\left(\mathrm{CaHPO}_{4} \cdot 2 \mathrm{H}_{2} \mathrm{O}\right)$ to transform to calcium-deficient hydroxyapatite ${ }^{28)}$, a more thermodynamically stable, hydrolysis-resistant compound. The reaction was proposed as follows ${ }^{28}$ :

$$
\begin{aligned}
& 6 \mathrm{CaHPO}_{4} \cdot 2 \mathrm{H}_{2} \mathrm{O}+(4-\mathrm{x}) \mathrm{Ca}^{2+} \rightarrow \\
& \mathrm{Ca}_{10-\mathrm{x}}\left(\mathrm{HPO}_{4}\right)_{\mathrm{x}}\left(\mathrm{PO}_{4}\right)_{6-\mathrm{x}}(\mathrm{OH})_{2-\mathrm{x}}+(8-2 \mathrm{x}) \mathrm{H}^{+} \\
& +(\mathrm{x}+10) \mathrm{H}_{2} \mathrm{O}
\end{aligned}
$$

Since the composition of the precipitate compound was similar to that of human teeth, and if a continuous mineralization process through the above reaction formula (3) could take place, the longevity of the therapeutic effect could be substantially prolonged. Nevertheless, further in vivo study needs to be conducted to evaluate the influences of dentinal fluids and pulpal pressure on the occlusive effect of DP-bioglass paste.

\section{CONCLUSION}

DP-bioglass paste was fabricated by mixing $30 \%$ phosphoric acid and DP-bioglass to treat dentin hypersensitivity. Consequently, homogeneous covering on exposed dentinal tubules and $60 \mu \mathrm{m}$ of sealing depth into the dentinal tubules could be observed. $\mathrm{CO}_{2}$ laser irradiation was employed to melt the DPbioglass paste and create about $10 \mu \mathrm{m}$ of sealing depth. Moreover, temperature rise during $\mathrm{CO}_{2}$ laser irradiation was below $5.5^{\circ} \mathrm{C}$.

\section{REFERENCES}

1) Gillam DG, Aris A, Bulman JS, Newman HN, Ley F. Dentine hypersensitivity in subjects recruited for clinical trials: Clinical evaluation, prevalence and intra-oral distribution. J Oral Rehabil 2002; 29: 226-231.

2) Kimura $Y$, Wilder-Smith $P$, Yonaga $K$, Matsumoto $K$. Treatment of dentine hypersensitivity by lasers: A review. J Clin Periodontol 2000; 27: 715-721.

3) Orchardson R, Collins WJ. Clinical features of hypersensitive teeth. Br Dent J 1987; 162: 253-256.

4) Matthews $\mathrm{B}$, Vongsavan $\mathrm{N}$. Interactions between neural and hydrodynamic mechanisms in dentine and pulp. Arch Oral Biol 1994; 39(Suppl): 87S-95S.

5) Liu HC, Lan WH, Hsieh CC. Prevalence and distribution of cervical dentin hypersensitivity in a population in Taipei, Taiwan. J Endod 1998; 24: 45-47.

6) Holland GR, Narhi MN, Addy M, Gangarosa L, Orchardson R. Guidelines for the design and conduct of clinical trials on dentine hypersensitivity. $\mathrm{J}$ Clin Periodontol 1997; 24: 808-813.

7) Rimondini L, Baroni C, Carrassi A. Ultrastructure of hypersensitive and non-sensitive dentine: A study on replica models. J Clin Periodontol 1995; 22: 899-902.

8) Absi EG, Addy M, Adams D. Dentine hypersensitivity: A study of the patency of dentinal tubules in sensitive and non-sensitive cervical dentine. $\mathrm{J}$ Clin Periodontol 1987; 14: 280-284.

9) Corona SA, Nascimento TN, Catirse AB, Lizarelli RF, Dinelli W, Palma-Dibb RG. Clinical evaluation of lowlevel laser therapy and fluoride varnish for treating cervical dentinal hypersensitivity. I Oral Rehabil 2003; 30: 1183-1189.

10) Brännström $M$. The hydrodynamic theory of dentinal pain: Sensation in preparations, caries, and the dentinal crack syndrome. J Endod 1986; 12: 453-457.

11) Wylie SG, Wilson PR. An investigation into the pressure transmitted to the pulp chamber on crown cementation: A laboratory study. J Dent Res 1994; 73: 1684-1689.

12) Ciaramicoli MT, Carvalho RC, Eduardo CP. Treatment of cervical dentin hypersensitivity using neodymium: yttrium-aluminum-garnet laser: Clinical evaluation. Lasers Surg Med 2003; 33: 358-362.

13) Marsilio AL, Rodrigues JR, Borges AB. Effect of the clinical application of the GaAlAs laser in the treatment of dentine hypersensitivity. J Clin Laser Med Surg 2003; 21: 291-296.

14) Gillam DG, Newman HN, Davies EH, Bulman JS, Troullos ES, Curro FA. Clinical evaluation of ferric oxalate in relieving dentine hypersensitivity. J Oral Rehabil 2004; 31: 245-250.

15) Frechoso CS, Menendez M, Guisasola C, Arregui I, Tejerina JM, Sicilia A. Evaluation of the efficacy of two potassium nitrate bioadhesive gels ( $5 \%$ and $10 \%$ ) in the treatment of dentine hypersensitivity: A randomized clinical trial. J Clin Periodontol 2003; 30: 315320 .

16) Duran I, Sengun A. The long-term effectiveness of five current desensitizing products on cervical dentine sensitivity. J Oral Rehabil 2004; 31: 351-356.

17) Lutins ND, Greco GW, McFall WT Jr. Effectiveness of sodium fluoride on tooth hypersensitivity with and without iontophoresis. J Periodontol 1984; 55: 285-288.

18) Suge $T$, Ishikawa $K$, Kawasaki $A$, Yoshiyama $M$, Asaoka K, Ebisu S. Effects of fluoride on the calcium phosphate precipitation method for dentinal tubule occlusion. J Dent Res 1995; 74: 1079-1085.

19) Suge T, Ishikawa K, Kawasaki A, Suzuki K, Matsuo $\mathrm{T}$, Noiri $\mathrm{Y}$, Imazato S, Ebisu S. Calcium phosphate precipitation method for the treatment of dentin hypersensitivity. Am J Dent 2002; 15: 220-226. 
20) Lee BS, Chang CW, Chen WP, Lan WH, Lin CP. In vitro study of dentin hypersensitivity treated by $\mathrm{Nd}$ : YAP laser and bioglass. Dent Mater 2005; 21: 511-519.

21) Tavares M, Depaola PF, Soparkar P. Using a fluoridereleasing resin to reduce cervical sensitivity. JADA 1994; 125: 1337-1342.

22) Lin CP, Tseng YC, Lin FH, Liao JD, Lan WH. Treatment of tooth fracture by medium-energy $\mathrm{CO}_{2}$ laser and DP-bioactive glass paste: The interaction of enamel and DP-bioactive glass paste during irradiation by $\mathrm{CO}_{2}$ laser. Biomaterials 2001; 22: 489-496.

23) Lin CP, Lee BS, Kok SH, Lan WH, Tseng YC, Lin FH. Treatment of tooth fracture by medium energy $\mathrm{CO}_{2}$ laser and DP-bioactive glass paste: Thermal behavior and phase transformation of human tooth enamel and dentin after irradiation by $\mathrm{CO}_{2}$ laser. J Mater Sci Mater Med 2000; 11: 373-381.

24) Lee BS, Lin CP, Lin FH, Lan WH. Ultrastructural changes of human dentin after irradiation by $\mathrm{Nd}$ :
YAG laser. Lasers Surg Med 2002; 30: 246-252.

25) Zach L, Cohen G. Pulp response to externally applied heat. Oral Surg Oral Med Oral Pathol 1965; 19: 515530 .

26) McNally KM, Gillings BR, Dawes JM. Dye-assisted diode laser ablation of carious enamel and dentine. Aust Dent J 1999; 44: 169-175.

27) Lin $\mathrm{CP}$, Lin FH, Tseng $\mathrm{YC}$, Kok SH, Lan WH, Liao JD. Treatment of tooth fracture by medium energy $\mathrm{CO}_{2}$ laser and DP-bioactive glass paste: Compositional, structural, and phase changes of DP-bioglass paste after irradiation by $\mathrm{CO}_{2}$ laser. Biomaterials 2000; 21: 637-643.

28) Ishikawa $K$, Suge $T$, Yoshiyama $M$, Kawasaki A, Asaoka K, Ebisu S. Occlusion of dentinal tubules with calcium phosphate using acidic calcium phosphate solution followed by neutralization. J Dent Res 1994; 73: 1197-1204. 